\title{
Previous Exposure to Psychostimulants Enhances the Reinstatement of Cocaine Seeking by Nucleus Accumbens AMPA
}

\author{
Nobuyoshi Suto',2, Lauren M Tanabe', Jennifer D Austin', Elizabeth Creekmore', Chauchau T Pham' \\ and Paul Vezina*, I \\ 'Department of Psychiatry, The University of Chicago, Chicago, IL, USA
}

\begin{abstract}
The effect of previous exposure to psychostimulants on the subsequent self-administration of cocaine as well as reinstatement of this behavior by priming infusions of AMPA into the nucleus accumbens (NAcc) was examined. Rats were exposed to five injections, one injection every third day, of either saline or amphetamine (AMPH: $1.5 \mathrm{mg} / \mathrm{kg}$, i.p.). Starting 10 days later, they were trained to selfadminister cocaine $(0.3 \mathrm{mg} / \mathrm{kg} /$ infusion, i.v. $)$ and subsequently tested under a progressive ratio (PR) schedule for 4 consecutive days. As expected, rats exposed to AMPH worked more and obtained more cocaine infusions than saline exposed controls on the PR test sessions. Following daily extinction sessions during which saline was substituted for cocaine, the effect of priming infusions of AMPA (0.0, 0.08 , or $0.8 \mathrm{nmol} / 0.5 \mu \mathrm{l} / \mathrm{side}$ ) into the NAcc was then examined on two tests: one conducted 4 days after the last cocaine PR test session (2-3 weeks after the last AMPH exposure injection) and the next 4 weeks later. Consistent with previous reports, NAcc AMPA dosedependently reinstated cocaine seeking on both tests regardless of exposure condition. Importantly, this priming effect of NAcc AMPA was significantly enhanced in AMPH compared to saline exposed rats on the first test conducted 2-3 weeks after AMPH. On the second test, conducted 4 weeks after cocaine, reinstatement was similarly enhanced in both groups to levels observed on the first test in AMPH exposed rats. These results indicate that both noncontingent (AMPH) and contingent (cocaine) exposure to psychostimulants enhances the reinstatement of cocaine seeking by NAcc AMPA and appears to do so in a time-dependent manner.

Neuropsychopharmacology (2004) 29, 2149-2159, advance online publication, 2 I July 2004; doi: I 0. I 038/sj.npp. I 300533
\end{abstract}

Keywords: amphetamine; cocaine; nucleus accumbens; AMPA; glutamate receptor; self-administration; reinstatement; progressive ratio schedule of reinforcement; sensitization; cross-sensitization

\section{INTRODUCTION}

One of the hallmarks of psychostimulant addiction is compulsive drug seeking with a tendency to relapse even after long periods of abstinence (Jaffe, 1990). In drugabstinent humans, a single exposure to the drug (Jaffe et al, 1989) or to drug-related cues (Childress et al, 1993) can trigger intense craving that often precipitates relapse. In animal models, the noncontingent administration of a drug or presentation of drug-related cues or a stressor reinstates extinguished operant responding for psychostimulants (Shalev et al, 2002).

\footnotetext{
* Correspondence: P Vezina, Department of Psychiatry, The University of Chicago, 584I S Maryland Avenue, MC 3077, Chicago, IL 60637, USA, Tel: + I 773702 2890, Fax: + I 7737020857

E-mail: pvezina@yoda.bsd.uchicago.edu

${ }^{2}$ Current address: Behavioral Neuroscience Branch, Intramural Research Program, NIDA/NIH/DHHS, Baltimore, MD 21224 , USA.

Received 2 March 2004; revised 21 June 2004; accepted 21 June 2004 Online publication: 23 June 2004 at http://www.acnp.org/citations/ Npp06230404099/default.pdf
}

It has long been known that the ability of psychostimulants to support self-administration is critically dependent on their ability to increase extracellular concentrations of dopamine (DA) in the nucleus accumbens (NAcc) (Di Chiara, 1995; Koob et al, 1998; Wise, 1998). As such, it is reasonable to suspect that NAcc DA may also underlie the ability of noncontingent injections of these drugs to reinstate extinguished self-administration behavior. Consistent with this view, systemic priming injections of DA receptor agonists (Wise et al, 1990; Self et al, 1996) or noncontingent infusions of DA into the NAcc (Cornish and Kalivas, 2000) reinstate cocaine seeking. Curiously, however, infusing a DA receptor antagonist into the NAcc blocks the reinstatement of cocaine seeking by NAcc DA (Cornish and Kalivas, 2000) but not by systemic cocaine (Cornish and Kalivas, 2000; McFarland and Kalivas, 2001). These results, together with others showing that cocaine infused into the NAcc or prefrontal cortex reinstates drug seeking (Park et al, 2002), suggest that actions of cocaine other than its increase of extracellular levels of NAcc DA are involved. 
While the NAcc constitutes the major subcortical terminal field of DA perikarya located in the ventral tegmental area, it also receives extensive glutamatergic projections directly from the prefrontal cortex and limbic structures such as the hippocampal formation and amygdala (Christie et al, 1987; Meredith et al, 1993). These structures have been implicated in the reinstatement of drug seeking by drug-paired stimuli (amygdala and hippocampus; Grimm and See, 2000; Vorel et al, 2001) and cocaine (prefrontal cortex; Park et al, 2002; McFarland et al, 2003) as have their glutamatergic projections to the NAcc. Thus, cocaine-induced reinstatement is associated with an increase in extracellular glutamate levels in the NAcc (McFarland et al, 2003). AMPA receptors appear to be specifically implicated because infusing AMPA into the NAcc reinstates drug seeking (Cornish et al, 1999; Cornish and Kalivas, 2000) while infusion of AMPA receptor antagonists into this site blocks the reinstatement produced by systemic cocaine, NAcc DA, or cocaine in the prefrontal cortex (Cornish and Kalivas, 2000; Park et al, 2002) as well as responding for cocaine-associated cues under a second-order schedule of reinforcement (Di Ciano and Everitt, 2001). NMDA receptor agonists and antagonists have been reported to produce mixed effects (Cornish et al, 1999; Cornish and Kalivas, 2000; Park et al, 2002). Collectively, these findings suggest an essential role for glutamate afferents in the NAcc and local AMPA receptors in particular in the reinstatement of drug seeking by cocaine.

Interestingly, NAcc AMPA receptors are also involved in the expression of locomotor sensitization by psychostimulants. For example, infusions of AMPA into the NAcc produce enhanced locomotion in animals exposed to cocaine 2-3 weeks earlier (Bell and Kalivas, 1996; Pierce et al, 1996a) and AMPA receptor antagonists administered systemically (Karler et al, 1991; Tzschentke and Schmidt, 1997; Jackson et al, 1998; Mead and Stephens, 1998; cf, Karler et al, 1994; Li et al, 1997) or into the NAcc (Pierce et al, 1996a; Bell et al, 2000) prevent the expression of locomotor sensitization by amphetamine (AMPH) and cocaine. When taken in light of the above findings and others showing that sensitization enhances the pursuit and self-administration of drugs (Vezina, 2004), these results suggest that previous exposure to psychostimulants should enhance the ability of NAcc AMPA to reinstate drug seeking. A link between sensitization and reinstatement of drug seeking has also been proposed by others (De Vries et al, 1998, 2002). The present experiments assessed this possibility.

\section{METHODS}

\section{Subjects}

Male Long-Evans rats (Harlan Sprague-Dawley, Madison, WI; Toconic, German Town, NY) weighing $250-275 \mathrm{~g}$ on arrival were used. They were individually housed with food and water freely available in a reverse cycle room (12-h light/12-h dark) for the duration of the experiment. Animals were always tested during the dark period of the light cycle.

\section{Apparatus}

In total, 15 chambers, each measuring $22 \times 43 \times 33 \mathrm{~cm}^{3}$, were used for cocaine self-administration. Each chamber was made of stainless-steel (rear and two side walls), a Plexiglas front hinged door and a tubular stainless-steel ceiling and floor. These chambers were placed in a plastic box that shielded animals from extraneous disturbances. White noise was supplied in each box by a ventilating fan. A lever $(5 \mathrm{~cm}$ above the floor $)$ and a stimulus light $(13.5 \mathrm{~cm}$ above the lever) were positioned on the right side wall. Each chamber was equipped with a liquid swivel system comprised of a steel-spring tether, a liquid swivel and an infusion pump (Razel Scientific Inc., Model, A.E) that allowed free movement of the animal in the chamber and delivery of drug upon depression of the lever. The tether was connected to the animal by screwing its captive collar onto the threaded portion of a custom-designed Lshaped Plastics One cannulae (20 gauge) secured to the animals skull (see Pierre and Vezina, 1997). Lever presses and drug infusions were recorded and controlled via an electrical interface by a computer using locally developed software.

\section{Drugs}

$\mathrm{S}(+)$-amphetamine sulfate (AMPH), (-)-cocaine hydrochloride (cocaine) and ( \pm )-alpha-Amino-3-hydroxy-5methylisoxazole-4-propinic acid hydrobromide (AMPA) were obtained from Sigma Inc. (Saint Louis, MO). Drugs were dissolved in sterile saline $(0.9 \% \mathrm{w} / \mathrm{v})$ for i.c., i.p., and i.v. routes of administration. Doses refer to the weight of the salt.

\section{Surgery}

For all surgical procedures, rats were anesthetized with a mix of ketamine $(100 \mathrm{mg} / \mathrm{kg}$, i.p.) and xylazine $(6 \mathrm{mg} / \mathrm{kg}$, i.p.). For intracranial implantation of cannulae, animals were placed in a stereotaxic instrument with the incisor bar positioned $5.0 \mathrm{~mm}$ above the interaural line (Pellegrino et al, 1979) and implanted with chronic bilateral guide cannulae (22 gauge, Plastics One, Roanoke, VA) aimed at the NAcc (A/P, + 3.4; L, \pm 1.5 ; DV, -7.5 from bregma and skull). Cannulae were angled at $10^{\circ}$ to the vertical and positioned $1 \mathrm{~mm}$ above the final injection site. After surgery, 28 gauge obturators were placed in the guide cannulae and rats were returned to their home cages for a 5-7 day recovery period.

For cocaine self-administration, rats were surgically implanted with an i.v. catheter into their right external jugular vein as described by Pierre and Vezina (1997). The intravenous catheter used was made of silastic tubing (Dow Corning, Inc.). Catheters were flushed daily with a $0.9 \%$ sterile saline solution containing $30 \mathrm{IU} / \mathrm{ml}$ heparin and $250 \mathrm{mg} / \mathrm{ml}$ ampicillin in order to promote patency. Seven rats (AMPH, four; saline, three) were dropped because their catheters became nonpatent or developed leaks.

All surgical procedures were conducted using aseptic techniques according to an approved IACUC protocol. 


\section{Design and Procedure}

The study consisted of five phases: exposure, cocaine selfadministration training, cocaine self-administration testing, extinction, and testing for reinstatement. The last two phases were repeated twice, once starting the day after the last cocaine self-administration session and again 4 weeks later. Rats were randomly assigned to different groups depending on exposure (AMPH or saline) and test for reinstatement $(0.0,0.08$, or $0.8 \mathrm{nmol} / \mathrm{side}$ of AMPA) conditions. Thus, rats in six different groups were tested: saline-saline, saline-AMPA 0.08, saline-AMPA 0.8, AMPHsaline, AMPH-AMPA 0.08, and AMPH-AMPA 0.8, where group name indicates the exposure condition first and the test for reinstatement condition second. Table 1 outlines the different experimental phases and the groups tested.

Exposure. Starting 3-5 days after arrival, animals were administered a total of five injections of AMPH $(1.5 \mathrm{mg} / \mathrm{kg}$, i.p.) or saline in their home cage, one injection every third day. Similar exposure regimens have been shown to produce sensitized locomotor and NAcc DA responses to a subsequent AMPH challenge injection (eg Vezina et al, 2002) as well as enhanced self-administration of AMPH (Lorrain et al, 2000; Vezina et al, 2002).

Cocaine self-administration training. Training for cocaine self-administration began 10 days after the final drug exposure injection, at least 3 days after animals received their i.v. catheters and 5 days after implantation of the intracranial guide cannulae. Cocaine self-administration sessions were held daily and lasted for $3 \mathrm{~h}$. In all cases, reinforced presses on the lever delivered an infusion of cocaine through the i.v. catheter $(0.3 \mathrm{mg} / \mathrm{kg} /$ infusion $)$. The cocaine solution was injected in volumes of $0.10-0.13 \mathrm{ml} /$ infusion at a rate of $1.6 \mathrm{ml} / \mathrm{min}$. For $15 \mathrm{~s}$ immediately following reinforced depressions of the lever, a stimulus light above the lever was lit and lever presses were recorded but did not lead to further infusions.

An experimenter-delivered priming infusion of cocaine $(0.3 \mathrm{mg} / \mathrm{kg}$, i.v. $)$ was given at the beginning of each session. The initial schedule used was a fixed ratio 1 (FR1) schedule of reinforcement and it was increased to an FR2 schedule once animals successfully administered an additional nine infusions within the 3-h session. Rats were then again required to self-administer an additional nine infusions within a 3-h session under the FR2 schedule. Animals that did not satisfy each of the FR1 and the FR2 criteria (ie nine infusions in a 3-h session) within 5 days were excluded from the study. In total, 22 rats were thus excluded (AMPH exposure, 12; saline exposure, 10). Days to satisfaction of the training criteria under each FR schedule were recorded.

Cocaine self-administration testing. Upon satisfactory completion of self-administration training under the FR schedules, rats were tested daily under a progressive ratio (PR) schedule of reinforcement for 4 days. Under this schedule, the number of responses required to obtain each successive infusion of cocaine was determined by ROUND $(5 \times \operatorname{EXP}(0.25 \times$ infusion number $)-5)$ to produce the following sequence of required lever presses: $1,3,6,9,12,17$, $24,32,42,56,73,95,124,161,208$, etc (Richardson and Roberts, 1996). The daily PR sessions were terminated when $1 \mathrm{~h}$ elapsed without a drug infusion and, as a result, generally lasted $3 \mathrm{~h}$ or less. The final ratio attained has been defined as the subject's break point (Richardson and Roberts, 1996). Priming infusions were not given during these sessions. The number of infusions obtained in each PR session was recorded.

Extinction 1. Starting the day following the cocaine selfadministration testing phase, all rats were subjected to extinction sessions for 3 consecutive days. In these sessions, saline was substituted for cocaine and animals were allowed to self-administer the saline under the PR schedule of reinforcement. Each extinction session lasted $3 \mathrm{~h}$ or less if $1 \mathrm{~h}$ elapsed without an infusion. The number of saline infusions obtained was recorded.

Upon completion of this phase, rats in each exposure group (AMPH or saline) were randomly divided into three subgroups defined by the test for reinstatement condition $(0.0,0.08,0.8 \mathrm{nmol} /$ side of AMPA).

Test for reinstatement 1 . On the day following extinction, the effect of a priming infusion of AMPA into the NAcc on the reinstatement of cocaine seeking was assessed. Rats were noncontingently administered bilateral infusions of either saline $(0.5 \mu \mathrm{l} /$ side $)$ or AMPA $(0.08$ or $0.8 \mathrm{nmol} / 0.5 \mu \mathrm{l} /$

Table I Outline of the Different Phases of the Experiment and the Groups Tested ${ }^{a}$

\begin{tabular}{|c|c|c|c|c|c|c|c|}
\hline \multirow{2}{*}{ Saline (33) } & & & & AMPA $0.08(\mathrm{II})$ & - & Saline (I I) & AMPA $0.08($ I I) \\
\hline & & & & AMPA 0.8 (9) & & Saline (9) & AMPA 0.8 (9) \\
\hline AMPH (3I) & & & & AMPA 0.8 (8) & & Saline (8) & AMPA 0.8 (8) \\
\hline
\end{tabular}

\footnotetext{
${ }^{a}$ Rats were surgically prepared (i.v. catheters and intracranial implants aimed at the NAcc) during the I0-day period separating the exposure phase and the cocaine selfadministration training phase. The duration of the different phases is shown in numbers of days. The n/group are shown in parentheses. On the tests for reinstatement, AMPA was noncontingently infused bilaterally into the NAcc. Indicated doses of AMPA are in nmol/ $0.5 \mu / /$ side.
} 
side) into the NAcc. Immediately after the priming infusion, animals were allowed to self-administer saline under the PR schedule of reinforcement for $3 \mathrm{~h}$ or less if $1 \mathrm{~h}$ elapsed without an infusion. The number of saline infusions obtained was recorded.

The doses of AMPA were in part selected based on the findings of Cornish et al (1999) and Cornish and Kalivas (2000) showing that cocaine seeking under an FR schedule of reinforcement can be reinstated by 0.4 but not $0.04 \mathrm{nmol} /$ side of AMPA in the NAcc.

Following this test, rats were left undisturbed in their home cages for a withdrawal period of 10-14 days.

Extinction 2. Starting the day after the 10-14 day withdrawal period, all rats were subjected to another series of daily extinction sessions for 12 consecutive days. The procedures used for these sessions were identical to those used for the Extinction I phase. The number of saline infusions obtained in each session was recorded.

Test for reinstatement 2 . On the day following extinction, the effect of a priming infusion of AMPA into the NAcc on the reinstatement of cocaine seeking was again assessed. The procedures used for this test were identical to those used in the first test for reinstatement. The number of saline infusions obtained was again recorded for each animal.

\section{Histology}

After completion of the experiment, rats were anesthetized with sodium pentobarbital and perfused via intracardiac infusion of saline and $10 \%$ formalin. Brains were removed and postfixed in $10 \%$ formalin. Coronal sections $(40 \mu \mathrm{m})$ were mounted onto gelatin-coated slides and subsequently stained with cresyl violet for verification of cannulae tip placements.

Only data obtained from animals with both cannula tips placed in the NAcc were retained for statistical analyses. A total of 14 animals were excluded because one or both injection cannula tips were found to be outside the NAcC (saline-saline, four; saline-AMPA 0.08, three; saline-AMPA 0.8 , one; AMPH-saline, two; AMPH-AMPA 0.08, two; AMPH-AMPA 0.8, 2). Thus, the number of animals retained in each group for statistical analyses was: saline-saline, 13; saline-AMPA 0.08, 11; saline-AMPA 0.8, nine; AMPH-saline, 14; AMPH-AMPA 0.08, nine; and AMPH-AMPA 0.8, eight. The location of the injection cannula tips in the NAcc for these animals is illustrated in Figure 1 with their group affiliation.

\section{Data Analyses}

The data obtained during the cocaine self-administration training phase (days to criterion) were analyzed with $t$-test for independent samples (AMPH and saline exposed). The data obtained during the cocaine self-administration testing phase (number of infusions obtained on each test day) were analyzed with one-way between one-way within ANOVA with exposure (two levels: AMPH and saline) as the between factors and days of testing (4) as the within factor. In order to assess the effects of extinction in the three Extinction 1 sessions, the number of saline infusions obtained was

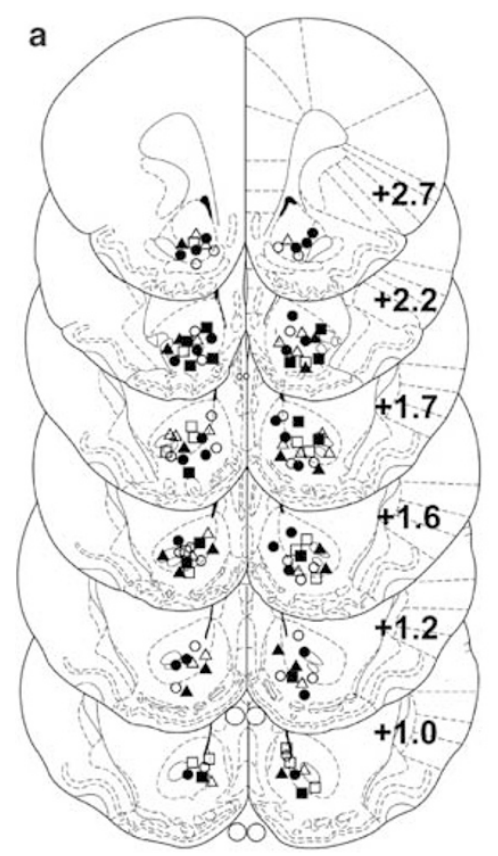

b

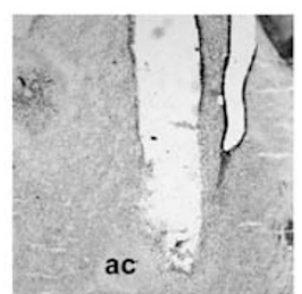

c

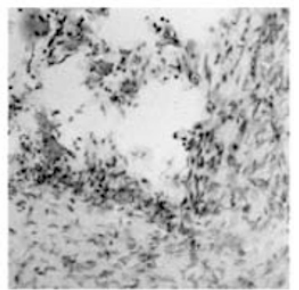

Figure I Injection cannula tip placements in the NAcc. Location of the injection cannula tips for rats included in the data analyses are illustrated in (a). Symbols refer to group affiliation: saline-saline $(O)$, saline-AMPA 0.08 $(\square)$, saline-AMPA $0.8(\triangle)$, AMPH-saline ( $)$ ), AMPH-AMPA $0.08(\square)$ and AMPH-AMPA $0.8(\mathbf{\Delta})$ where group name indicates the exposure condition first and the test for reinstatement condition second. Line drawings are from Paxinos and Watson (1997). Numbers to the right indicate $\mathrm{mm}$ from bregma. $n=8-14 /$ group. The photomicrographs illustrate an injection cannula tip just medial to the anterior commissure (ac) in the NAcc (b) and cresyl violet stained cells in close proximity to it (c). They are from a rat administered $0.8 \mathrm{nmol} / 0.5 \mu$ AMPA. Magnification is $\times 2.5$ in (b) and $\times 20$ in (c).

compared to the number of cocaine infusions obtained on the last day of cocaine self-administration testing using a one-way between one-way within ANOVA with exposure (two levels: AMPH and saline) as the between factor and days of testing (4) as the within factor. In order to determine whether subgroup differences existed on the last day of extinction, data obtained on this day were further analyzed with two-way between ANOVA with exposure (two levels: AMPH and saline) and priming (three levels: 0.0 , 0.08 , and 0.8 ) as the between factors. Data obtained in the Extinction 2 sessions were analyzed with two-way between one-way within ANOVA with exposure (two levels: AMPH and saline) and priming (three levels: $0.0,0.08$, and 0.8 ) as the between factors and days of testing (12) as the within factor. Again, data obtained on the last day of extinction were further analyzed with two-way between ANOVA as for the Extinction 1 data and compared to the data obtained on the last day of cocaine self-administration testing using a two-way between one way within ANOVA with the above between factors and days of testing (2) as the within factor. Data obtained in the Reinstatement 1 and 2 tests (number of saline infusions obtained) were analyzed separately each with two-way between ANOVA with exposure (two levels: AMPH and saline) and priming (three levels: 0.0, 0.08, and 0.8 ) as the between factors. The number of infusions obtained in a PR session was used for statistical analysis 
rather than the number of presses required for each reinforcement or the final ratios obtained since the latter were, by definition, generated from an exponential function (Richardson and Roberts, 1996). All analyses together with post hoc Tukey HSD tests were conducted with Statistica (1999 edition) statistical software.

\section{RESULTS}

\section{Cocaine Self-Administration Training}

In agreement with previous reports (Mendrek et al, 1998; Lorrain et al, 2000; Suto et al, 2002, 2003a; Vezina et al, 2002), rats in the two exposure groups readily satisfied the self-administration training criteria and did so in similar manner regardless of exposure condition. On average, rats in the two groups satisfied each of the FR1 and FR2 criteria in 1-2 days (Figure 2a). The $t$-test comparisons conducted on these data revealed no significant effects. Days to achieve the FR1 criterion: $t_{62}=0.24$, NS. Days to achieve the FR2 criterion: $\mathrm{F}_{62}=1.15$, NS.

\section{Cocaine Self-Administration Testing Under the PR Schedule of Reinforcement}

Again consistent with previous reports (Mendrek et al, 1998; Lorrain et al, 2000; Suto et al, 2002, 2003a; Vezina et al, 2002), rats exposed to systemic AMPH worked more and obtained significantly more cocaine infusions than saline exposed controls when tested under the PR schedule of reinforcement (Figure $2 \mathrm{~b}$ ). The ANOVA conducted on these data revealed significant effects of exposure $\left(\mathrm{F}_{1,62}=14.74\right.$, $P<0.001)$. Neither the effect of day $\left(\mathrm{F}_{3,186}=1.49\right.$, NS) nor the exposure $\times$ day interaction $\left(\mathrm{F}_{3,186}=0.54, \mathrm{NS}\right)$ achieved statistical significance.

\section{Extinction 1}

Replacing cocaine with saline in these extinction sessions significantly reduced lever pressing in both AMPH and saline exposed rats. The ANOVA comparing the number of saline infusions obtained in these sessions to the number of cocaine infusions obtained on the last day of cocaine selfadministration testing revealed significant effects of day $\left(\mathrm{F}_{3,186}=17.98, \quad P<0.001\right)$ and exposure $\left(\mathrm{F}_{1,62}=7.51\right.$, $P<0.01)$ and a significant exposure $\times$ day interaction $\left(\mathrm{F}_{3,186}=5.40, P<0.01\right)$. The latter effects reflect the fact that, compared to saline exposed controls, AMPH exposed rats showed higher levels of responding during cocaine selfadministration and that the extinction procedure diminished responding and eventually obscured this difference between groups. Post hoc Tukey HSD comparison revealed that rats in the two exposure groups did not differ significantly on the last day of extinction.

As rats in each of the two exposure groups were then divided into three subgroups based on test for reinstatement condition, an additional ANOVA was conducted to determine whether group differences in number of saline infusions obtained existed on the last day of extinction as a result of subgroup allocation. No significant differences between the six resulting experimental groups were found (Figure 3a). The ANOVA conducted on these data revealed a Cocaine Self-Administration Training
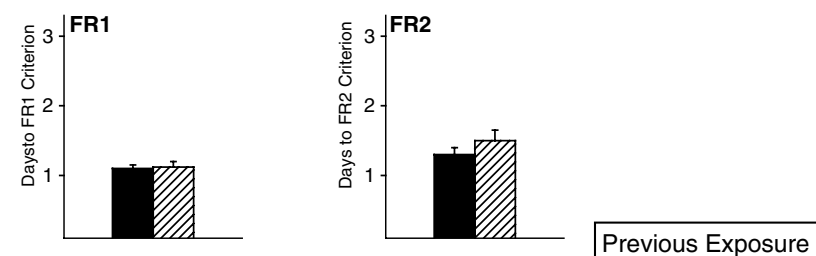

b Cocaine Self-Administration Training
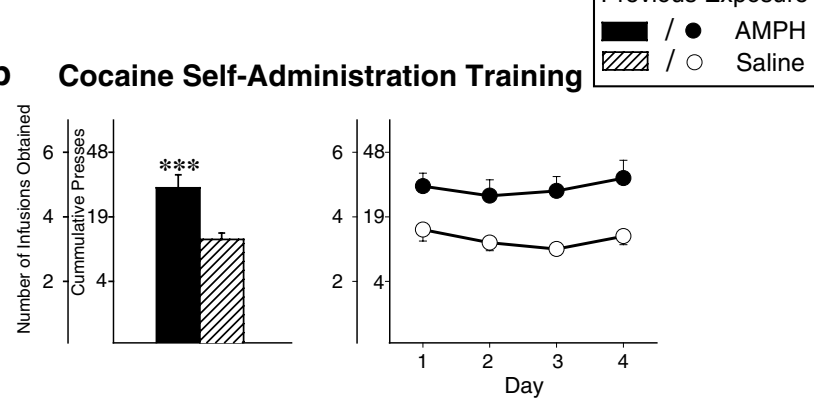

Figure 2 Cocaine self-administration training and testing. (a) Cocaine self-administration training under the FRI (left) and the FR2 (right) schedules of reinforcement. Data are shown as the mean (+ SEM) number of days rats took to reach criterion (nine self-administered infusions within a 3-h session) for each schedule. Following a single priming infusion of cocaine $(0.3 \mathrm{mg} / \mathrm{kg}$, i.v. $)$, rats were allowed to self-administer nine additional infusions of the drug on each schedule. Exposure condition (AMPH or saline, indicated at abscissae) did not significantly influence the number of days to achieve criterion under either schedule of reinforcement. (b) Previous exposure to AMPH enhanced the self-administration of cocaine under the PR schedule of reinforcement. Data are shown as mean ( \pm SEM) number of cocaine infusions obtained. The cumulative number of presses required to obtain these infusions is also shown. The bar graph to the left was derived from means of the values obtained for each subject on each of the four PR test days. These are shown to the right as group means. ****, $P<0.00$ I vs saline exposed rats as revealed by post hoc Tukey HSD comparisons following ANOVA. $n=31-33$ per $\mathrm{AMPH}$ and saline exposure condition.

no significant effects: exposure $\left(\mathrm{F}_{1,58}=0.13, \mathrm{NS}\right)$, priming $\left(\mathrm{F}_{2,58}=1.01, \mathrm{NS}\right)$, and exposure $\times$ priming interaction $\left(\mathrm{F}_{2,58}=0.56, \mathrm{NS}\right)$.

Reanalysis with ANOVA of the cocaine self-administration test data taking subgroup allocation into account revealed a significant effect of exposure as expected $\left(\mathrm{F}_{1,58}=12.98, \quad P<0.001\right)$ but no significant differences between the three subgroups in each exposure condition. Neither the effect of priming $\left(\mathrm{F}_{2,58}=0.28\right.$, NS) nor the exposure $\times$ priming interaction $\left(\mathrm{F}_{2,58}=0.88, \mathrm{NS}\right)$ achieved statistical significance.

Thus, no significant differences between the three reinstatement test groups were observed in each exposure condition during cocaine self-administration testing. Furthermore, rats in the six experimental groups did not differ significantly from one another on the last day of extinction prior to the first test for reinstatement.

Test for Reinstatement 1: Non-Contingent Exposure to Systemic AMPH Enhances the Reinstatement of Cocaine Seeking by NAcc AMPA

Consistent with previous reports (Cornish et al, 1999; Cornish and Kalivas, 2000), infusing AMPA into the 
a

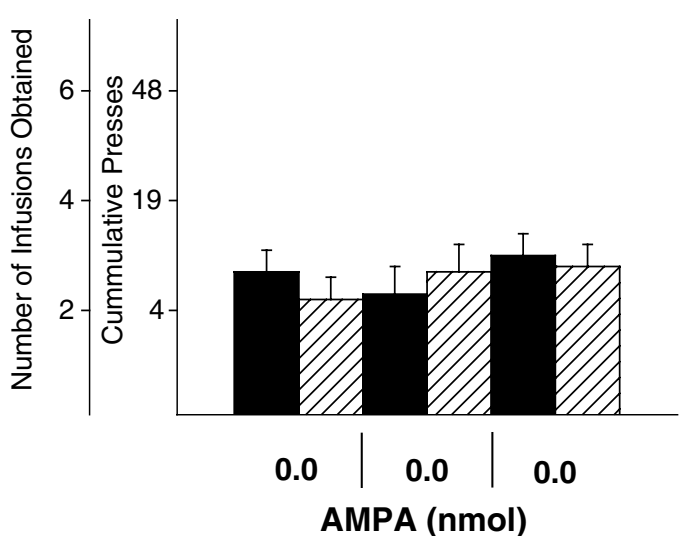

C

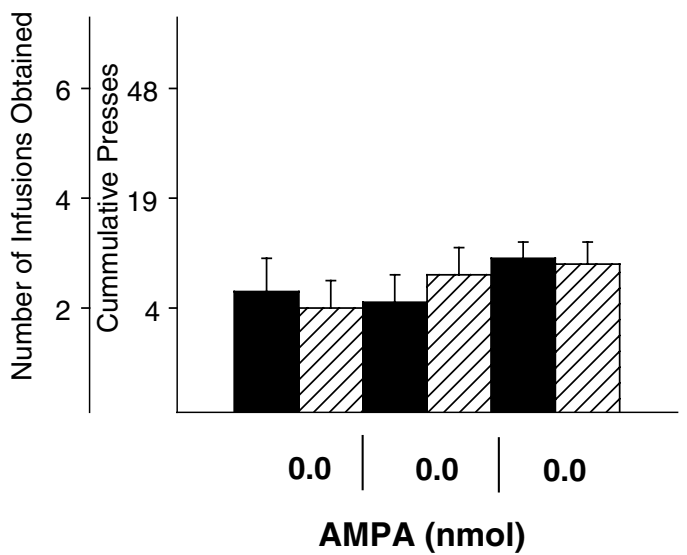

b

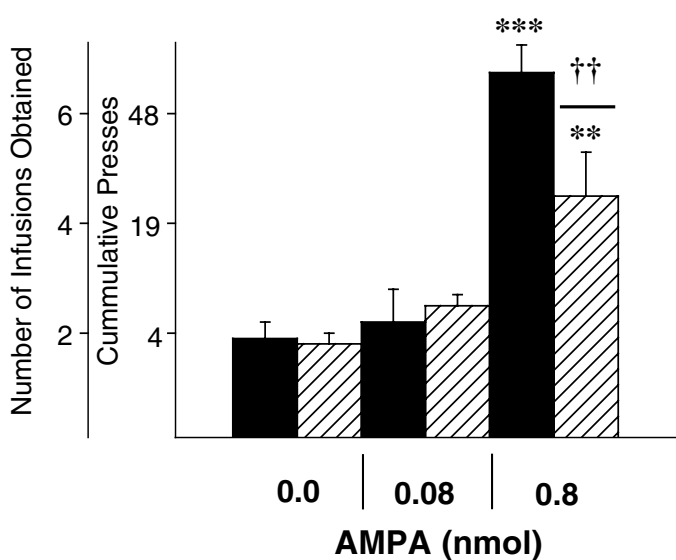

d

Reinstatement Test 2

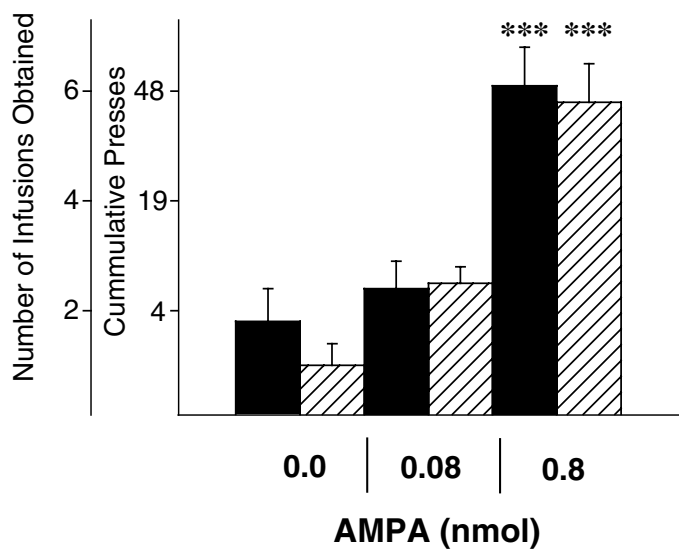

\begin{tabular}{|l} 
Previous Exposure \\
AMPH \\
AMITA Saline
\end{tabular}

Figure 3 Previous exposure to psychostimulants enhances the reinstatement of drug seeking by NAcc AMPA. (a) Number of saline infusions obtained under the PR schedule of reinforcement on the last day of Extinction I by rats in the different groups. Data are shown as mean ( + SEM) number of saline infusions obtained. The cumulative number of presses required to obtain these infusions is also shown. AMPA was not administered during extinction. No significant between-group differences were found. (b) Number of saline infusions obtained on the first test for reinstatement conducted 4 days after the last cocaine self-administration session and 2-3 weeks after the last AMPH exposure injection. Previous exposure to noncontingent AMPH significantly enhanced the reinstatement of drug seeking by NAcc AMPA. Data are shown as specified in (a). $* *, P<0.01, * * *, P<0.00$ I vs saline-saline. ${ }^{\dagger \dagger}, P<0.0$ I vs AMPH-AMPA 0.8 as revealed by post hoc Tukey HSD comparisons following ANOVA. (c) Number of saline infusions obtained under the PR schedule of reinforcement on the last day of Extinction 2 by rats in the different groups. Data are shown as specified in (a). Again, AMPA was not administered during extinction and no significant between-group differences were found. (d) Number of saline infusions obtained on the second test for reinstatement conducted $>4$ weeks after the last cocaine self-administration session. Previous exposure to contingent cocaine significantly enhanced the reinstatement of drug seeking by NAcc AMPA to levels observed in AMPH exposed rats on both tests for reinstatement. Data are shown as specified in (a). ****, $P<0.00$ I vs saline-saline as revealed by post hoc Tukey HSD comparisons following ANOVA. In all cases, group names indicate the exposure condition first and the test for reinstatement condition second. $n=8-\mid 4 /$ group.

NAcc dose-dependently reinstated cocaine seeking regardless of exposure condition (Figure $3 \mathrm{~b}$ ). Importantly, this priming effect of NAcc AMPA was significantly greater in rats previously exposed to AMPH when compared to the saline exposed controls. The ANOVA conducted on these data revealed significant effects of exposure $\left(\mathrm{F}_{1,58}=4.16, \quad P<0.05\right) \quad$ and priming $\quad\left(\mathrm{F}_{2,58}=38.78\right.$, $P<0.001)$ as well as a significant exposure $\times$ priming interaction $\left(\mathrm{F}_{2,58}=5.16, P<0.01\right)$. Post hoc Tukey HSD comparisons showed that both AMPH and saline exposed rats tested with the $0.8 \mathrm{nmol}$ dose of AMPA obtained significantly more saline infusions than rats in the remaining groups tested with either saline or the $0.08 \mathrm{nmol}$ dose of AMPA $(P<0.01-0.001)$. These comparisons also showed, however, that at the $0.8 \mathrm{nmol}$ dose of AMPA, rats previously exposed to AMPH obtained significantly more saline infusions than their saline exposed counterparts $(P<0.01)$. 


\section{Extinction 2}

In these extinction sessions initiated 10-14 days following the first test for reinstatement, all rats at first showed elevated levels of lever pressing for saline that approached those exhibited during cocaine self-administration testing. Interestingly, this effect was enhanced both in rats previously exposed to AMPH and in rats tested with the $0.8 \mathrm{nmol}$ dose of AMPA on the first reinstatement test, suggesting long-term effects on drug-seeking precipitated by return to the drug-taking environment of previous exposure to AMPH and NAcc AMPA. The ANOVA conducted on these data revealed significant effects of day $\left(\mathrm{F}_{11,638}=9.30, \quad P<0.001\right)$ and priming $\left(\mathrm{F}_{2,58}=8.12\right.$, $P<0.001)$ as well as a very close to statistically significant effect of exposure $\left(F_{1,58}=3.91, P=0.052\right)$. None of the interactions achieved statistical significance: exposure $\times$ priming $\left(\mathrm{F}_{2,58}=1.13\right.$, NS), exposure $\times$ day $\left(\mathrm{F}_{11,638}=0.89\right.$, $\mathrm{NS})$, priming $\times$ day $\left(\mathrm{F}_{22,638}=1.43\right.$, NS), and exposure $\times$ priming $\times$ day $\left(\mathrm{F}_{22,638}=0.56, \mathrm{NS}\right)$.

The effects of priming infusion and exposure diminished with days so that by the last day of extinction, no significant differences between groups were observed and responding had diminished to levels significantly lower than those observed on the last day of cocaine self-administration testing (Figure 3c). Two-way between ANOVA conducted on the data collected on the last day of extinction revealed no significant effects: exposure $\left(\mathrm{F}_{1,58}=0.19\right.$, NS), priming $\left(\mathrm{F}_{2,58}=2.45, \mathrm{NS}\right)$, exposure $\times$ priming interaction $\left(\mathrm{F}_{2,58}=0.55\right.$, NS). A two-way between one-way within ANOVA comparing these data to those obtained on the last day of cocaine self-administration testing revealed significant effects of exposure $\left(\mathrm{F}_{1,58}=4.65, P<0.05\right)$ and days $\left(\mathrm{F}_{1,58}=31.09, \quad P<0.001\right)$ as well as a significant exposure $\times$ days interaction $\left(\mathrm{F}_{1,58}=7.58, \quad P<0.01\right)$, the latter reflecting the significant exposure effect on the last day of cocaine self-administration and its absence on the last day of extinction.

\section{Test for Reinstatement 2: Contingent Exposure to Intravenous Cocaine Enhances the Reinstatement of Cocaine Seeking by NAcc AMPA in a Time-Dependent Manner}

As in the first test for reinstatement, infusing AMPA into the NAcc again dose-dependently reinstated cocaine seeking on this test (Figure 3d). However, on this test conducted over 4 weeks after cocaine self-administration, reinstatement was similarly enhanced in both AMPH and saline exposed groups to levels observed on the first test in AMPH exposed rats. These results suggest that, as already reported for locomotor sensitization (Hooks et al, 1994; Phillips and Di Ciano, 1996; Lorrain et al, 2000), contingent exposure to cocaine may have enhanced responding in rats previously exposed to saline and done so in a time dependent manner. The ANOVA conducted on these data revealed significant effects of priming $\left(\mathrm{F}_{2,58}=35.23, P<0.001\right)$. Neither the effect of exposure $\left(F_{1,58}=0.78, N S\right)$ nor the exposure $\times$ priming interaction $\left(\mathrm{F}_{2,58}=0.35\right.$, NS) achieved statistical significance. Post hoc Tukey HSD comparisons showed that the $0.8 \mathrm{nmol}$ dose of AMPA significantly increased the number of saline infusions obtained relative to saline and the $0.08 \mathrm{nmol}$ dose $(P<0.001)$ and did so equally in AMPH and saline exposed rats. AMPH exposed rats responded similarly to the $0.8 \mathrm{nmol}$ dose of AMPA on both tests for reinstatement (the number of saline infusions obtained in each test did not differ significantly, $t_{7}=0.65, \mathrm{NS}$ ), indicating that the enhancement observed on the first test did not diminish with time.

\section{NAcc AMPA Exposure Controls}

In the Extinction 2 sessions, there was evidence that exposure to NAcc AMPA on the first test for reinstatement produced a long-term enhancement of the drug seeking precipitated by return to the drug-taking environment. While this evidence was absent by the last extinction session, it is nonetheless possible that exposure to AMPA on the first test for reinstatement, and not contingent exposure to cocaine, enhanced responding to AMPA in saline exposed rats on the second test. To assess this possibility, rats in four additional groups (saline-AMPA 0.08, nine; saline-AMPA 0.8, nine; AMPH-AMPA 0.08, eight; and, AMPH-AMPA 0.8, nine) were surgically prepared as described above and tested in a manner identical to that illustrated in Table 1 with the exception that on the first test for reinstatement, these rats were administered NAcc saline only. Importantly, these animals were exposed to NAcc AMPA only on the second test for reinstatement.

Infusing saline into the NAcc on the first test for reinstatement produced no increase in cocaine seeking in these animals (Figure $4 \mathrm{a}$ ). When compared to the salinesaline controls described above and illustrated in Figure 3b, no differences in number of saline infusions obtained was detected. The ANOVA conducted on these data revealed no statistically significant effects: exposure $\left(F_{1,56}=0.002, \mathrm{NS}\right)$, priming $\left(\mathrm{F}_{2,56}=1.05\right.$, NS), exposure $\times$ priming interaction $\left(\mathrm{F}_{2,56}=0.57, \mathrm{NS}\right)$. On the second test for reinstatement (Figure 4b), AMPA again dose-dependently reinstated cocaine seeking, did so equally in both AMPH and saline exposed rats, and produced levels of responding similar to those observed previously and illustrated in Figure $3 \mathrm{~d}$. These results indicate that exposure to NAcc AMPA on the first test for reinstatement could not be responsible for the enhanced responding observed in the saline exposed rats on this test. The ANOVA conducted on these data revealed a significant effect of priming $\left(\mathrm{F}_{2,56}=39.56, P<0.001\right)$. Neither the effect of exposure $\left(F_{1,56}=0.95\right.$, NS) nor the exposure $\times$ priming interaction $\left(\mathrm{F}_{2,56}=0.32, \mathrm{NS}\right)$ achieved statistical significance. Post hoc Tukey HSD comparisons showed the $0.8 \mathrm{nmol}$ dose of AMPA significantly increased the number of saline infusions obtained relative to the saline and $0.08 \mathrm{nmol}$ dose priming injections and did so equally in both AMPH and saline exposed rats $(P<0.001)$.

\section{DISCUSSION}

In the present experiments, it was found that NAcc AMPA dose-dependently reinstates cocaine seeking, a finding consistent with previous reports. Importantly, the present results show unequivocally for the first time that this reinstatement is enhanced in rats previously exposed noncontingently (AMPH) or contingently (cocaine) to 


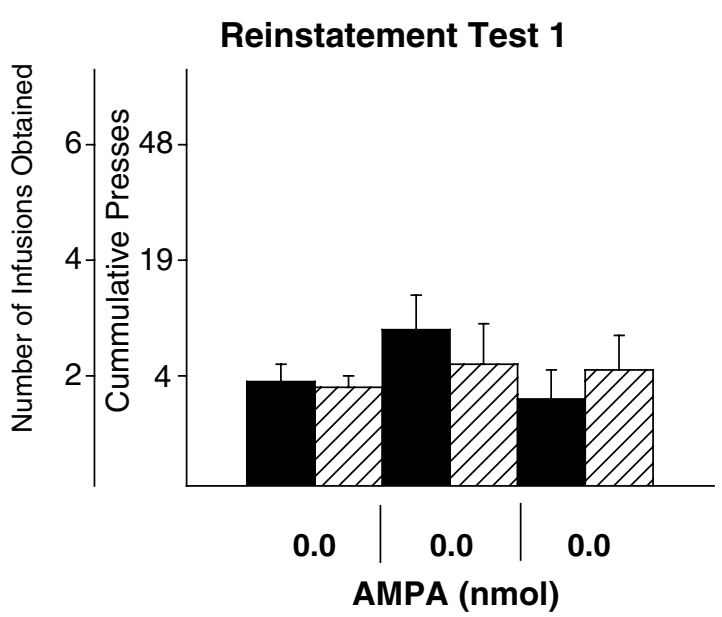

b

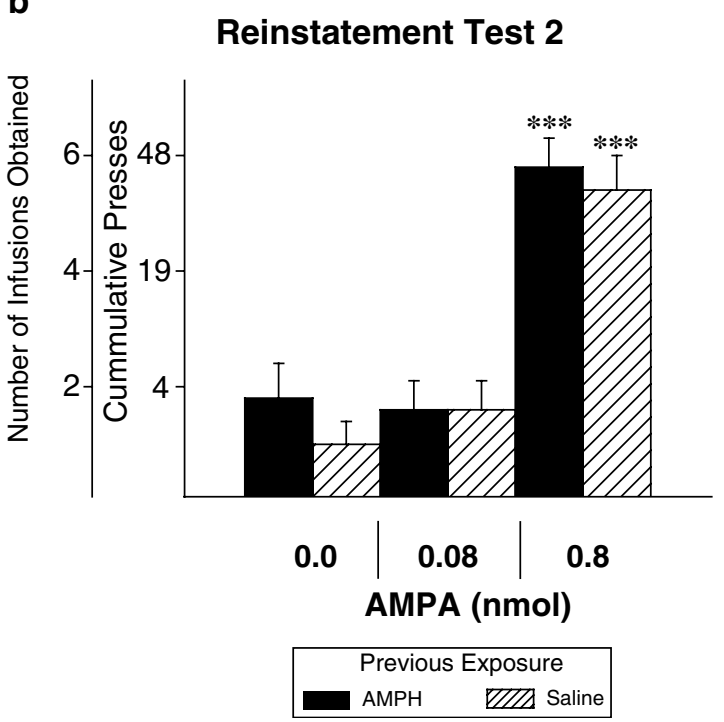

Figure 4 NAcc AMPA exposure controls. (a) Number of saline infusions obtained on the first test for reinstatement. AMPA was not administered to these rats on this test. Data are shown as mean ( + SEM) number of saline infusions obtained under the PR schedule of reinforcement following NAcc saline. The cumulative number of presses required to obtain these infusions is also shown. No between-group differences were detected. (b) Number of saline infusions obtained on the second test for reinstatement. AMPA was administered on this test. Remaining details are as specified in (a). Thus, the enhanced reinstatement observed in saline-AMPA 0.8 rats could not have been due to exposure to NAcc AMPA on the first test for reinstatement. ****, $P<0.00$ I vs saline-saline as revealed by post hoc Tukey HSD comparisons following ANOVA. $n=8-9 /$ group.

psychostimulant drugs. The finding that contingent exposure to cocaine enhanced NAcc AMPA reinstatement over 4 weeks, but not 4 days, later indicates that this effect is time dependent.

It is known that NAcc AMPA receptors are involved in the expression of locomotor sensitization by psychostimulants. Infusing AMPA into the NAcc produces enhanced locomotion in rats exposed to cocaine 2-3 weeks earlier (Bell and Kalivas, 1996; Pierce et al, 1996a) and AMPA receptor antagonists prevent the expression of locomotor sensitization by amphetamine (Karler et al, 1991; Tzschentke and
Schmidt, 1997; Mead and Stephens, 1998; cf, Li et al, 1997) and cocaine (Pierce et al, 1996a; Jackson et al, 1998; Bell et al, 2000; cf, Karler et al, 1994; Li et al, 1997). The present results are consistent with these findings and extend them to the reinstatement of drug seeking. Thus, previous exposure to psychostimulant drugs not only enhances the ability of NAcC AMPA to produce locomotion but also enhances its ability to reinstate drug seeking even after an extended withdrawal period. There have been several reports showing that exposure to a sensitizing regimen of drug injections produces long-term enhancements in animals' predisposition to self-administer drugs (Vezina, 2004). The present findings show that sensitization also figures importantly in the reinstatement of drug taking and that NAcc AMPA receptors play a critical role. Importantly, they indicate that sensitized individuals, at least in part because of neuroadaptations involving NAcc AMPA receptors, are at even greater risk for relapse even after they have been drug free for an extended period of time. Such a link between sensitization and reinstatement of drug seeking has been proposed by others (De Vries et al, 1998, 2002). However, in these latter experiments it is difficult to assess this relation directly because the experimental designs used do not allow the comparison, on the test for reinstatement, of drug exposed $v s$ saline exposed rats and animals with equivalent experience with the self-administration procedures. The procedures used in the present experiments are not so constrained.

Cue- and cocaine-induced reinstatement of drug seeking has in fact been reported to increase with the passage of time since the last day of drug self-administration (TranNguyen et al, 1998; Grimm et al, 2001, 2003; cf, DerocheGamonet et al, 2003). While the relationship of these findings to sensitization is not fully established (see Vezina, 2004), they are nonetheless consistent with the present results showing enhanced reinstatement by NAcc AMPA long (2-3 weeks for noncontingent $\mathrm{AMPH}$ and $>4$ weeks for contingent cocaine) but not soon (4 days for contingent cocaine) after drug exposure. Similarly, the magnitude of the enhanced NAcc AMPA induced locomotor response observed in cocaine exposed rats is greater when animals are tested later rather than soon after drug exposure (Pierce et al, 1996a,b). A number of neuroadaptations have been found to increase with the passage of time since drug exposure, including BDNF protein levels (and presumably BDNF-mediated synaptic plasticity; Grimm et al, 2003) as well as DA and glutamate overflow in response to drug challenge (Vanderschuren and Kalivas, 2000) and these may very well contribute to the progressively enhanced ability of psychostimulant drugs to reinstate drug seeking. It remains to be determined whether and how such neuroadaptations modulate the ability of NAcc AMPA to reinstate drug seeking. Neuroadaptations that are observed in the period soon after drug exposure and subsequently decay $\left(\right.$ eg $\mathrm{D}_{2} \mathrm{DA}$ autoreceptor subsensitivity, Wolf et al, 1993; $\mathrm{D}_{1}$ DA receptor supersensitivity, Henry and White, 1991) are probably not involved.

Assessments of the effect of exposing animals to AMPH or cocaine on AMPA receptor subunit protein levels in the NAcc have yielded conflicting results. Thus, exposure to AMPH has been reported to lead 2 weeks later to decreased GluR1 and GluR2 AMPA receptor subunit mRNA and 
protein levels in the NAcc, leaving GluR3 and GluR4 protein levels unchanged (Lu et al, 1997; Lu and Wolf, 1999). On the other hand, exposure to cocaine 17-90 days earlier has been reported to either slightly increase GluR1 (Churchill et al, 1999; Scheggi et al, 2002; Lu et al, 2003) and GluR2 (Lu et al, 2003) protein levels, leave GluR1 (Fitzgerald et al, 1996; Ghasemzadeh et al, 1999) and GluR2 (Fitzgerald et al, 1996; Churchill et al, 1999; Ghasemzadeh et al, 1999; Scheggi et al, 2002) protein and mRNA levels unchanged and decrease GluR3 and GluR4 mRNA levels (Ghasemzadeh et al, 1999). In another study, GluR1 and GluR2/3 protein levels were not increased 1 week following cocaine self-administration unless animals were subjected to an extinction procedure during the withdrawal period (Sutton et al, 2003). While multiple factors can certainly be evoked to explain the different results obtained, the range of findings together with the small magnitude of the effects reported $(20-50 \%$ of control) suggests that factors other than changes in the overall expression of AMPA receptor subunits are responsible for the enhanced ability of NAcc AMPA to produce locomotion and reinstate drug seeking. A number of reports have shown, for example, that phosphorylation of different sites including some on the GluR1 AMPA receptor subunit increases peak open probability (Banke et al, 2000), unitary conductance (Derkach et al, 1999) and trafficking of the receptor into the synapse (Hayashi et al, 2000). To the extent that these events have been suggested to accompany synaptic plasticity in different preparations (eg Benke et al, 1998; Lee et al, 2000, 2003), it is conceivable that they may underlie enhanced behavioral responsiveness to NAcc AMPA in a manner that is unrelated to overall AMPA receptor subunit expression. Interestingly, $D_{1} D A$ receptor activation increases the insertion of the GluR1 AMPA receptor subunit into the cell surface, and possibly synaptic sites, of NAcc cultured neurons through a pathway dependent on protein kinase A (Chao et al, 2002; Mangiavacchi and Wolf, 2004). Together with recent findings showing that enhanced, but not acute, NAcc AMPA induced reinstatement of drug seeking is DAdependent and accompanied by enhanced DA overflow in this site (Suto et al, 2003b; cf, Pierce et al, 1996a), these findings suggest a mechanism (enhanced $\mathrm{D}_{1} \mathrm{DA}$ receptor activation) whereby previous drug exposure could enhance NAcc AMPA receptor mediated transmission and generation of behavior. It also remains to be determined, however, whether or not enhanced AMPA receptor function is itself responsible for the enhanced drug-induced DA overflow observed in the NAcc of sensitized animals.

Activation of AMPA receptors is associated with fast excitatory transmission in neurons of the NAcc (eg Pennartz and Kitai, 1991). Thus, reports showing that NAcc AMPA produces locomotion and reinstates drug seeking (see Introduction), that these effects are enhanced in drug exposed animals (Pierce et al, 1996a; present results), and that phosphorylation of different substrates can enhance AMPA receptor function (see above) are consistent with the view that enhanced stimulation of neurons in the NAcc is associated with enhanced behavioral output. Other reports have shown, however, that previous exposure to sensitizing regimens of cocaine injections produces decreased excitability in medium spiny neurons in the NAcc (Zhang et al, 1998) and long-term depression at glutamatergic synapses onto these neurons (Thomas et al, 2001). It is, on the surface, difficult to accommodate both of these apparently opposing views. Importantly and consistent with enhanced excitatory transmission, the blockade of AMPA receptors in the NAcc prevents the expression of locomotor sensitization by cocaine (Pierce et al, 1996a; Bell et al, 2000). In addition, the reinstatement of drug seeking by NAcc AMPA is not mimicked by infusions into this site of the local anesthetic procaine, a finding that does not support depolarization block of neurons in the NAcc as a mechanism of action of AMPA (Cornish et al, 1999). It is likely that insights will be gleaned by continued characterization of the multiple effects of exposure to drugs on the different neuronal populations of the NAcc. For example, in the study of Thomas et al (2001), synaptic depression following repeated cocaine was observed in the shell but not the core of the NAcc while the core but not the shell subregion has been reported to contribute to reinstatement of cocaine seeking (McFarland and Kalivas, 2001). In addition, while some NAcc medium spiny neurons undergo whole cell and synaptic depression following drug exposure (Zhang et al, 1998; Thomas et al, 2001), NAcc interneurons display a more robust increase in GluR1 surface expression in response to D1 DA receptor activation (Chao et al, 2002) and may represent important targets for AMPA in the context of the present findings. Enhanced stimulation of these interneurons could possibly lead to enhanced inhibition of select medium spiny neurons (Pennartz and Kitai, 1991). It remains to be determined how different neurons and the AMPA receptors they express are specifically targeted, whether differences exist between medium spiny neurons and interneurons regarding the insertion of AMPA receptors into synapses and how DA interacts with and modulates these effects. Answers to these questions will help elucidate not only how neuroadaptations involving AMPA receptors can place some individuals at greater risk for reinstatement but also and more importantly what therapeutic interventions can be developed to protect them.

\section{ACKNOWLEDGEMENTS}

This research was supported by grant DA-09397 (PV) from the USPHS.

\section{REFERENCES}

Banke TG, Bowie D, Lee HK, Huganir RL, Schousboe A, Traynelis SF (2000). Control of GluR1 AMPA receptor function by cAMPdependent protein kinase. J Neurosci 20: 89-102.

Bell K, Duffy P, Kalivas PW (2000). Context-specific enhancement of glutamate transmission by cocaine. Neuropsychopharmacology 23: $335-344$.

Bell K, Kalivas PW (1996). Context-specific cross-sensitization between systemic cocaine and intra-accumbens AMPA infusion in the rat. Psychopharmacology 127: 377-383.

Benke TA, Luthi A, Isaac JTR, Collingridge GL (1998). Modulation of AMPA receptor unitary conductance by synaptic activity. Nature 393: 793-797.

Chao SZ, Ariano MA, Peterson DA, Wolf ME (2002). D1 dopamine receptor stimulation increases GluR1 surface expression in nucleus accumbens neurons. J Neurochem 83: 704-712.

Childress AR, Ehrman RN, Rohsenow D, Robbins SJ, O'Brien CP (1993). Classically conditioned factors in drug dependence. 
In: Lowinson J, Ruiz P, Millman $\mathrm{R}$ (eds). Comprehensive Textbook of Substance Abuse. Williams and Wilkins: Baltimore. pp 56-69.

Christie MJ, Summers RJ, Stephenson JA, Cook CJ, Beart PM (1987). Excitatory amino acid projections to the nucleus accumbens septi in the rat: a retrograde transport study utilizing $\mathrm{D}[3 \mathrm{H}]$ aspartate and $[3 \mathrm{H}] \mathrm{GABA}$. Neuroscience 22: 425-439.

Churchill L, Swanson CJ, Urbina M, Kalivas PW (1999). Repeated cocaine alters glutamate receptor subunit levels in the nucleus accumbens and ventral tegmental area of rats that develop behavioral sensitization. J Neurochem 72: 2397-2403.

Cornish JL, Duffy P, Kalivas PW (1999). A role for nucleus accumbens glutamate transmission in the relapse to cocaineseeking behavior. Neuroscience 93: 1359-1367.

Cornish JL, Kalivas PW (2000). Glutamate transmission in the nucleus accumbens mediates relapse in cocaine addiction. $J$ Neurosci 20: RC89.

De Vries TJ, Schoffelmeer ANM, Binnekade R, Mulder AH, Vanderschuren LJMJ (1998). Drug-induced reinstatement of heroin- and cocaine-seeking behaviour following long-term extinction is associated with expression of behavioural sensitization. Eur J Neurosci. 10: 3565-3571.

De Vries TJ, Schoffelmeer ANM, Binnekade R, Raaso H, Vanderschuren LJMJ (2002). Relapse to cocaine- and heroinseeking behavior mediated by dopamine D2 receptors is timedependent and associated with behavioral sensitization. Neuropsychopharmacology 26: 18-26.

Derkach V, Barria A, Soderling TR (1999). $\mathrm{Ca}^{2+} /$ calmodulin-kinase II enhances channel conductance of $\alpha$-amino-3-hydroxy-5methyl-4-isoxazolepropionate type glutamate receptors. Proc Natl Acad Sci 96: 3269-3274.

Deroche-Gamonet V, Martinez A, Le Moal M, Piazza PV (2003). Relationships between individual sensitivity to CS- and cocaineinduced reinstatement in the rat. Psychopharmacology 168: 201-207.

Di Chiara G (1995). The role of dopamine in drug abuse viewed from the perspective of its role in motivation. Drug Alcohol Depend 38: 95-137.

Di Ciano P, Everitt BJ (2001). Dissociable effects of antagonism of NMDA and AMPA/KA receptors in the nucleus accumbens core and shell on cocaine-seeking behavior. Neuropsychopharmacology 25: 341-360.

Fitzgerald LW, Ortiz J, Hamedani AG, Nestler EJ (1996). Drugs of abuse and stress increase the expression of GluR1 and NMDAR1 glutamate receptor subunits in the rat ventral tegmental area: common adaptations among cross-sensitizing agents. J Neurosci 16: $274-282$.

Ghasemzadeh MB, Nelson LC, Lu X-Y, Kalivas PW (1999). Neuroadaptations in ionotropic and metabotropic glutamate receptor mRNA produced by cocaine treatment. J Neurochem 72: 157-165.

Grimm JW, Hope BT, Wise RA, Shaham Y (2001). Neuroadaptation. Incubation of cocaine craving after withdrawal. Nature 412: 141-142.

Grimm JW, Lu L, Hayashi T, Hope BT, Su TP, Shaham Y (2003). Time-dependent increases in brain-derived neurotrophic factor protein levels within the mesolimbic dopamine system after withdrawal from cocaine: implications for incubation of cocaine craving. J Neurosci 23: 742-747.

Grimm JW, See RE (2000). Dissociation of primary and secondary reward-relevant limbic nuclei in an animal model of relapse. Neuropsychopharmacology 22: 473-479.

Hayashi Y, Shi SH, Esteban JA, Piccini A, Poncer JC, Malinow R (2000). Driving AMPA receptors into synapses by LTP and CaMKII: requirement for GluR1 and PDZ domain intereaction. Science 287: 2262-2267.

Henry DJ, White FJ (1991). Repeated cocaine administration causes persistent enhancement of $D_{1}$ dopamine receptor sensitivity within the rat nucleus accumbens. J Pharmacol Exp Ther 258: 882-890.

Hooks MS, Duffy P, Striplin C, Kalivas PW (1994). Behavioral and neurochemical sensitization following cocaine self-administration. Psychopharmacology 115: 265-272.

Jackson A, Mead AN, Rocha BA, Stephens DN (1998). AMPA receptors and motivation for drug: effect of the selective antagonist NBQX on behavioural sensitization and on selfadministration in mice. Behav Pharmacol 9: 457-467.

Jaffe JH (1990). Drug addiction and drug abuse. In: Gilman AG, Rall TW, Nies AS, Taylor P (eds). Goodman and Gilman's The Pharmacological Basis of Therapeutics. Pergamon: New York. pp 522-573.

Jaffe JH, Cascella NG, Kumor KM, Sherer MA (1989). Cocaineinduced cocaine craving. Psychopharmacology 97: 59-64.

Karler R, Calder LD, Bedingfield JB (1994). Cocaine behavioral sensitization and the excitatory amino acids. Psychopharmacology 115: 305-310.

Karler R, Calder LD, Turkanis SA (1991). DNQX blockade of amphetamine behavioral sensitization. Brain Res 552: 295-300.

Koob GF, Sanna PP, Bloom FE (1998). Neuroscience and addiction. Neuron 21: 467-476.

Lee HKL, Barbarosie M, Kameyama K, Bear MF, Huganir RL (2000). Regulation of distinct AMPA receptor phosphorylation sites during bidirectional synaptic plasticity. Nature 405: 955-959.

Lee HKL, Takamiya K, Han JS, Man H, Kim CH, Rumbaugh G et al (2003). Phosphorylation of the AMPA receptor GluR1 subunit is required for synaptic plasticity and retention of spatial memory. Cell 112: 631-643.

Li Y, Vartanian AJ, White FJ, Xue CJ, Wolf ME (1997). Effects of the AMPA receptor antagonist NBQX on the development and expression of behavioral sensitization to cocaine and amphetamine. Psychopharmacology 134: 266-276.

Lorrain DS, Arnold GM, Vezina P (2000). Previous exposure to amphetamine increases incentive to obtain the drug: long-lasting effects revealed by the progressive ratio schedule. Behav Brain Res 107: 9-19.

Lu L, Grimm JW, Shaham Y, Hope BT (2003). Molecular neuroadaptations in the accumbens and ventral tegmental area during the first 90 days of forced abstinence from cocaine selfadministration in rats. J Neurochem 85: 1604-1613.

Lu W, Chen H, Xue CJ, Wolf ME (1997). Repeated amphetamine administration alters the expression of mRNA for AMPA receptor subunits in rat nucleus accumbens and prefrontal cortex. Synapse 26: 269-280.

Lu W, Wolf ME (1999). Repeated amphetamine administration alters AMPA receptor subunit expression in rat nucleus accumbens and medial prefrontal cortex. Synapse 32: 119-131.

Mangiavacchi S, Wolf ME (2004). D1 dopamine receptor stimulation increases the rate of AMPA receptor insertion onto the surface of cultured nucleus accumbens neurons through a pathway dependent on protein kinase A. J Neurochem 88: 1261-1271.

McFarland K, Kalivas PW (2001). The circuitry mediating cocaineinduced reinstatement of drug-seeking behavior. J Neurosci 21: 8655-8663.

McFarland K, Lapish CC, Kalivas PW (2003). Prefrontal glutamate release into the core of the nucleus accumbens mediates cocaineinduced reinstatement of drug-seeking behavior. J Neurosci 23: 3531-3537.

Mead AN, Stephens DN (1998). AMPA-receptors are involved in the expression of amphetamine-induced behavioural sensitization, but not in the expression of amphetamine-induced conditioned activity in mice. Neuropharmacology 37: 1131-1138.

Mendrek A, Blaha CD, Phillips AG (1998). Pre-exposure of rats to amphetamine sensitizes self-administration of this drug under a progressive ratio schedule. Psychopharmacology 135: 416-422. 
Meredith GE, Pennartz CM, Groenewegen HJ (1993). The cellular framework for chemical signalling in the nucleus accumbens. Prog Brain Res 99: 3-24.

Park WK, Bari AA, Jey AR, Anderson SM, Spealman RD, Rowlett JK et al (2002). Cocaine administered into the medial prefrontal cortex reinstates cocaine-seeking behavior by increasing AMPA receptor-mediated glutamate transmission in the nucleus accumbens. J Neurosci 22: 2916-2925.

Paxinos G, Watson C (1997). The Rat Brain in Stereotaxic Coordinates: Compact, 3rd edn. Academic Press: San Diego, CA.

Pellegrino LJ, Pellegrino AS, Cushman AJ (1979). A Stereotaxic Atlas of the Rat Brain. Plenum Press: New York, NY.

Pennartz CMA, Kitai ST (1991). Hippocampal inputs to identified neurons in an in vitro slice preparation of the rat nucleus accumbens: evidence for feed-forward inhibition. J Neurosci 11: 2838-2847.

Phillips AG, Di Ciano P (1996). Behavioral sensitization is induced by intravenous self-administration of cocaine by rats. Psychopharmacology 124: 279-281.

Pierce RC, Bell K, Duffy P, Kalivas PW (1996a). Repeated cocaine augments excitatory amino acid transmission in the nucleus accumbens only in rats having developed behavioral sensitization. J Neurosci 16: 1550-1560.

Pierce RC, Duffy P, Kalivas PW (1996b). Changes in excitatory amino acid transmission in the nucleus accumbens associated with behavioral sensitization to cocaine during early withdrawal. Neurosci Net article \# 1996-008.

Pierre PJ, Vezina P (1997). Predisposition to self-administer amphetamine: the contribution of response to novelty and prior exposure to the drug. Psychopharmacology 129: 277-284.

Richardson NR, Roberts DC (1996). Progressive ratio schedules in drug self-administration studies in rats: a method to evaluate reinforcing efficacy. J Neurosci Methods 66: 1-11.

Scheggi S, Mangiavacchi S, Masi F, Gambarana C, Tagliamonte A, De Montis MG (2002). Dizocilpine infusion has a different effect in the development of morphine and cocaine sensitization: behavioral and neurochemical aspects. Neuroscience 109: 267-274.

Self DW, Barnhart WJ, Lehman DA, Nestler EJ (1996). Opposite modulation of cocaine-seeking behavior by D1- and D2-like dopamine receptor agonists. Science 271: 1586-1589.

Shalev U, Grimm JW, Shaham Y (2002). Neurobiology of relapse to heroin and cocaine seeking: a review. Pharmacol Rev 54: 1-42.

Suto N, Austin JD, Tanabe LM, Kramer MK, Wright DA, Vezina P (2002). Previous exposure to VTA amphetamine enhances cocaine self-administration under a progressive ratio schedule in a $\mathrm{D}_{1}$ dopamine dependent manner. Neuropsychopharmacology 27: 970-979.

Suto N, Pham CT, Baker LK, Vezina P (2003b). Enhanced reinstatement of drug seeking by AMPA in amphetamine pre-exposed rats requires dopamine receptor activation in the nucleus accumbens. Soc Neurosci Abstr 29: 112.9 Manuscript submitted.

Suto N, Tanabe LM, Austin JD, Creekmore E, Vezina P (2003a). Previous exposure to VTA amphetamine enhances cocaine selfadministration under a progressive ratio schedule in an NMDA, AMPA/kainate, and metabotropic glutamate receptor-dependent manner. Neuropsychopharmacology 28: 629-639.

Sutton MA, Schmidt EF, Choi KH, Schad CA, Whisler K, Simmons $\mathrm{D}$ et al (2003). Extinction-induced upregulation in AMPA receptors reduces cocaine-seeking behavior. Nature 421: 70-75.

Thomas MJ, Beurrier C, Bonci A, Malenka RC (2001). Long-term depression in the nucleus accumbens: a neural correlate of behavioral sensitization to cocaine. Nature Neurosci 4: 12171223.

Tran-Nguyen LT, Fuchs RA, Coffey GP, Baker DA, O'Dell LE, Neisewander JL (1998). Time-dependent changes in cocaineseeking behavior and extracellular dopamine levels in the amygdala during cocaine withdrawal. Neuropsychopharmacology 19: 48-59.

Tzschentke TM, Schmidt WJ (1997). Interactions of MK-801 and GYKI 52466 with morphine and amphetamine in place preference conditioning and behavioural sensitization. Behav Brain Res 84: 99-107.

Vanderschuren LJ, Kalivas PW (2000). Alterations in dopaminergic and glutamatergic transmission in the induction and expression of behavioral sensitization: a critical review of preclinical studies. Psychopharmacology 151: 99-120.

Vezina P (2004). Sensitization of midbrain dopamine neuron reactivity and the self-administration of psychomotor stimulant drugs. Neurosci Biobehav Rev 27: 827-839.

Vezina P, Lorrain DS, Arnold GM, Austin JD, Suto N (2002). Sensitization of midbrain dopamine neuron reactivity promotes the pursuit of amphetamine. J Neurosci 22: 4654-4662.

Vorel SR, Liu X, Hayes RJ, Spector JA, Gardner EL (2001). Relapse to cocaine-seeking after hippocampal theta burst stimulation. Science 292: 1175-1178.

Wise RA (1998). Drug-activation of brain reward pathways. Drug Alcohol Depend 51: 13-22.

Wise RA, Murray A, Bozarth MA (1990). Bromocriptine selfadministration and bromocriptine reinstatement of cocainetrained and heroin-trained lever pressing in rats. Psychopharmacology 100: 355-360.

Wolf ME, White FJ, Nassar R, Brooderson RJ, Khansa MR (1993). Differential development of autoreceptor subsensitivity and enhanced dopamine release during amphetamine sensitization. J Pharmacol Exp Ther 264: 249-255.

Zhang XF, Hu XT, White FJ (1998). Whole-cell plasticity in cocaine withdrawal: reduced sodium currents in nucleus accumbens neurons. J Neurosci 18: 488-498. 